\section{C CASE CONTROL STUDY ON PHTHALATE EXPOSURE AND REPRODUCTIVE HEALTH}

'L Caporossi, 'S Capanna, 'M De Rosa, ${ }^{2}$ D'Alessandro, ${ }^{3} \mathrm{C}$ Prestigiacomo, ${ }^{1} \mathrm{~B}$ Papaleo. ${ }^{1}$ National Institute for Insurance against Accidents at work- Department of Occupational and Environmental Medicine, Epidemiology and Hygiene, Monteporzio Catone (RM), Italy; ${ }^{2}$ Centro Sicurezza Lavoro, Pavona (RM), Italy; ${ }^{3}$ Department of Surgical sciences and Translational Medicine- UOD Occupational Medicine Saint Andrew Hospital, Medicine and Psychology Faculty, University of Rome 'La Sapienza'. Rome, Italy

\subsection{6/oemed-2018-ICOHabstracts. 1234}

Introduction Phthalates are plasticizing agents present in different production cycles (plastics, rubber, paints, cosmetics), some of them have shown toxicity for reproduction. Infertility is a pathological condition with multifactorial aetiology, where exposure to chemicals can be an important component.

Methods It was conducted a case/control study by recruiting 172 couples within a centre for assisted fertilisation, to which were collected urine samples and was administered a questionnaire to frame clinical anamnesis, habits and styles life. The sample dropped to 87 women and 76 men, excluding those who had a diagnosis unrelated to potential exposure to xenoestrogens. The determination of urinary metabolites was conducted through the use of HPLC/MS/MS; for diethylhexylphthalate

(DEHP) were monitored: mono (2ethylhexyl)-phthalate (MEHP) and mono(2-ethyl-5-hidroxyhexyl)-phthalate (MEHHP), for diethylphthalate (DEP) was monitored monoethylphtalate (MEP), for butylbenzylphthalate (BBzP) was monitored monobenzylphtalate (MBzP), for di-n-butylphthalate $(\mathrm{DnBP})$ was monitored monobutylphtalate $(\mathrm{MnBP})$. The results obtained were compared with those of 80 men and 90 women with at least one child obtained without hormonal therapy and with a time to pregnancy $<12$ months, paired by age.

Results The average levels of phthalate metabolites ( $\mu \mathrm{g} / \mathrm{g}$ creat) showed, by applying the test of Mann-Whitney, significant difference between cases and controls: for females MBzP 13.4 vs 2.0, MnBP 76.6 vs 3.0, MEHP and MEHHP 34.8 vs 7.2, MEP 569,.5 vs 198.0; for males MBzP 16.4 vs 3.4, MnBP 69.8 vs 9.1, MEHP and MEHHP 39.6 vs 9.1, MEP 340.6 vs 135.5. The analysis by the test of Wilcoxon showed that there is a significant difference between males and females (higher) in the values of MEP both between cases than controls.

Conclusion The interest in the characterisation of exposure to phthalates is certainly growing and the data obtained indicated a higher level, statistically significant, exposure in subjects with ipofertility. Risk source and clinical significance call for further investigations.

\section{7d WHAT ABOUT PREGNANT WORKERS WHEN THERE ARE CMR SUBSTANCES IN THE WORKPLACE}

Andrea Hiddinga-Schipper*, IEH Oirbons. Arbo Unie, Utrecht, The Netherlands

\subsection{6/oemed-2018-ICOHabstracts. 1235}

Introduction Carcinogenic, mutagenic and reprotoxic substances are often referred to as one group, due to the fact that a substance may present all three types of hazards, but also due to similarities in classification and in legal approach. CMRs are chronically toxic and have serious impacts on health. For workers with a pregnancy wish, pregnant workers and for the breast feeding workers employers should focus on zero exposure, by for example exemption from work. But if this is not possible a risk assessment is needed.

Method Directive 92/85/EEC on safety and health at work of pregnant and breastfeeding workers states that for all activities liable to involve a specific risk of exposure to the agents, processes or working conditions, the employer shall assess the nature, degree and duration of exposure, in order to assess risks to safety/health and possible effect on the pregnancy or breastfeeding workers. This risk assessment should be based on a coherent methodology supported by information collected systematically and measured data. In this presentation, a stepwise approach is presented on how the classification and the risk assessment, can be carried out, and how the assessment can be translated into the decision making process in terms of type and priority of control measures.

Results The results will show that mechanism of action of the substances, and studies on which a OEL might have been set (critical studies) are very important, when setting a reliable strategy for risk control. The different ways for exposure assessment will also be presented.

Discussion The approach will not only present the possibilities but also the difficulties for employers on dealing with these CMR substances and their workers. Several examples will be shown to illustrate the process and the discussions that might occur.

\section{SEMEN QUALITY AMONG WELDERS OCCUPATIONALLY EXPOSED TO LEAD AND CADMIUM IN AN EGYPTIAN SHIPBUILDING FACILITY}

${ }^{1}$ YM Youssef, ${ }^{1} \mathrm{AE}$ Fahim*, ${ }^{2} \mathrm{MM}$ Hassan, ${ }^{1} \mathrm{MF}$ Abbas. ${ }^{1}$ Departments of Community Medicine, Faculty of Medicine, Suez Canal University, Ismailia, Egypt; ${ }^{2}$ Departments of Andrology, Faculty of Medicine, Suez Canal University, Ismailia, Egypt

\subsection{6/oemed-2018-ICOHabstracts. 1236}

Introduction There is an increase in problems of the reproductive system in human males. This could be due to lifestyle factors, and chemical exposure in the work environment. Occupational activities involve constant exposure to toxic agents and may have a detrimental effect on human reproduction. This study aimed at assessing the semen quality among exposed workers to lead and cadmium.

Methods According to the inclusion criteria (at least 2 years of work exposure, age 20-45, non-smokers) 21 male workers (exposed group) in a welding unit at a shipbuilding facility in Ismailia Egypt and 42 office workers (control group) with the same criteria were compared. Personal, medical, reproductive and occupational histories were taken. Blood lead and cadmium concentrations were determined by atomic absorption spectrophotometer with Zeeman background correction (Perkin Elmer). Analysis of semen samples was performed in accordance with World Health Organisation criteria. P-value less than 0.05 were considered statistically significant in data analysis.

Results The blood level of lead and cadmium for the welding workers was $45.75 \pm 9.78 \mu \mathrm{g} / \mathrm{dl}$ and $1.68 \pm 1.60$, respectively, which was significantly higher than the control group 12.65 \pm 3.78 and $0.15 \pm 0.22 \quad(\mathrm{p}<0.001)$. Sperm counts of welding workers were $31.12 \pm 22.97$ millions $/ \mathrm{ml}$ lower than those of the control group were $50.80 \pm 39.56$ millions $/ \mathrm{ml} \quad(\mathrm{p}=0.016)$ and also sperm motility was decreased in exposed workers compared to controls $(\mathrm{p}=0.003)$. The sperm motility showed a negative correlation with blood lead content in workers. Blood concentration correlated with the number of years of exposure to welding. 